\title{
Avaliação da atividade cicatrizante do jucá (Caesalpinia ferrea Mart. ex Tul. var. ferrea) em lesões cutâneas de caprinos
}

\begin{abstract}
OLIVEIRA, A.F. ${ }^{*}$ BATISTA, J.S.; PAIVA, E.S.; SILVA, A.E.; FARIAS, Y.J.M.D.; DAMASCENO, C.A.R.; BRITO, P.D.; QUEIROZ, S.A.C.; RODRIGUES, C.M.F.; FREITAS, C.I.A.

Departamento de Ciências Animais, Universidade Federal Rural do Semi- Árido - UFERSA, BR 110, Km 47, Caixa Postal 137, Bairro Presidente Costa e Silva, CEP: 59.625-900, Mossoró-Brasil *andreia.f.o@bol.com.br; jaelsoares@hotmail.com; drerikapaiva@hotmail.com; anderson_euffrasio@hotmail.com; yvesjivago@hotmail.com; caiodamasceno@hotmail.com; parmenedesdbrito@hotmail.com; silvinhajprn@hotmail.com; cmonadeli@hotmail. com; ibere@ufersa.edu.br
\end{abstract}

\begin{abstract}
RESUMO: O objetivo deste estudo foi demonstrar os efeitos do tratamento tópico do jucá (Caesalpinia ferrea) em feridas cutâneas. Quinze caprinos machos sem raça definida foram divididos em 3 grupos de acordo com o pós-cirúrgico (7ํ, 14e e 21ㅇdias). As feridas experimentais foram tratadas com a pomada composta pela casca da Caesalpinia ferrea em pó misturada com a vaselina estéril e as do grupo controle apenas com a vaselina esterilizada. A aplicação diária da pomada e da vaselina estéril foi realizada sobre ferida circular padronizada de $16 \mathrm{~cm}^{2}$ de área na região torácica de cada animal. As avaliações das feridas foram feitas do ponto de vista clínico, bacteriológico, morfométrico e histopatológico nos períodos pré-determinados (7o, 14ํ e 21ㅇ dias). Morfometricamente, as feridas do controle apresentaram áreas cirúrgicas menores e grau de contração maior que as do grupo tratado, entretanto, histologicamente, houve completa epitelização das feridas tratadas no 21 o dia, enquanto que as feridas do grupo controle necessitavam de mais tempo para resolução do processo cicatricial. No exame microbiológico realizado no momento da produção da ferida, não se observou crescimento bacteriano e no momento das biópsias, identificou-se a presença de bactérias da família Enterobacteriaceae e Staphylococcus aureus, sendo que a partir do $14^{\circ}$ dia observou-se Staphylococcus aureus apenas no grupo controle. A utilização tópica da pomada de Caesalpinia ferrea apresentou eficiência significativa no auxílio da reparação cicatricial de feridas cutâneas de caprinos.
\end{abstract}

Palavras-chave: ferida, cicatrização, caprinos, Caesalpinia ferrea

\begin{abstract}
Evaluation of the Brazilian ironwood (Caesalpinia ferrea Mart. ex Tul. var. ferrea) healing activity on cutaneous lesions of goats. The aim of this study was to demonstrate the effects of the topical treatment with Brazilian ironwood (Caesalpinia ferrea) on cutaneous wounds. Fifteen male mongrel goats were divided into 3 groups according to the postoperative period $\left(\left(7^{\text {th }}, 14^{\text {th }}\right.\right.$ and $21^{\text {st }}$ days $)$. The experimental wounds were treated with an ointment composed of Brazilian wood powder bark mixed with sterile vaseline, whereas controls were only treated with sterile Vaseline. The ointment and the sterile vaselin were daily applied on a standardized circular wound $\left(16 \mathrm{~cm}^{2}\right.$ area) in the thoracic region of each animal. Clinical, bacteriological, morphometric and histopathological evaluations were performed in the wounds at predetermined periods $\left(7^{\text {th }}\right.$, $14^{\text {th }}$ and $21^{\text {st }}$ postoperative days). Morphometrically, control wounds had smaller surgical areas and greater degree of contraction than those from the treated group. However, histologically, there was a complete epithelialization of the treated wounds on the $21^{\text {st }}$ day, whereas control wounds required longer time for healing. In the microbiological evaluation performed at the moment of wound production, there was no bacterial growth. During biopsies, Enterobacteriaceae bacteria and Staphylococcus aureus were identified; from the $14^{\text {th }}$ day, the latter was only observed in the control group. The topical use of Caesalpinia ferrea ointment was significantly efficient to help healing cutaneous wounds in goats.
\end{abstract}

Key words: wound, healing, goats, Caesalpinia ferrea

Recebido para publicação em 23/03/2009

Aceito para publicação em 18/03/2010

Rev. Bras. PI. Med., Botucatu, v.12, n.3, p.302-310, 2010. 


\section{INTRODUÇÃO}

A cicatrização é um fenômeno natural de reorganização dos tecidos orgânicos que se inicia a partir da perda tecidual e no qual o tecido lesado é substituído por tecido conjuntivo vascularizado (Brasileiro Filho, 1998). É processo dinâmico envolvendo fenômenos bioquímicos e fisiológicos que se comportam de forma harmoniosa para promover a restauração tissular (Mandelbaum et al., 2003), que pode ser dividido em fases distintas, caracterizadas por população celular predominante, seguindo sequência conservada de eventos que se sobrepõem no tempo e incluem inflamação, proliferação e remodelação tecidual (Clark, 1996).

As propriedades terapêuticas dos princípios e medicamentos fitoterápicos começam a ganhar cada vez mais espaço no tratamento veterinário, demonstrado através do aumento da pesquisa de produtos naturais para auxiliar a cicatrização. Dentre as plantas estudadas, pode-se citar o jucá (Caesalpinia ferrea Martius ex Tul var. ferrea) que é uma árvore leguminosa nativa do Brasil, amplamente distribuída principalmente no Norte e Nordeste (Bragança, 1996; Lorenzi, 2002). Tem sido relatado o uso na medicina popular para tratamento de afecções bronco-pulmonares, diabetes, reumatismo, câncer, distúrbios gastrintestinais, diarréia, inflamação e dor (Balbach, 1972; Bragança, 1996; Hashimoto, 1996; Nakamura, 2002; Frasson et al., 2003; Gomes, 2003).

Algumas pesquisas mostram que o jucá possui atividade antifúngica e antibacteriana (Lima et al., 1997; Ximenes, 2004), antiulcerogênica (Bacchi \& Sertie, 1994; Bacchi et al., 1995) e antiinflamatória, bem como, propriedades analgésicas (Carvalho et al., 1996).

No estado do Rio Grande do Norte, o pó da casca da Caesalpinea ferrea é bastante usado pela população para o tratamento de feridas cutâneas. Assim, a utilização e comercialização da farinha de diversos tecidos, como por exemplo, a casca da Caesalpinia ferrea para aplicações na medicina popular, desperta o interesse desta planta para estudos biotecnológicos e farmacológicos (Ximenes, 2004).

Diante ao exposto, o presente estudo teve por objetivo avaliar a cicatrização de feridas cutâneas abertas em caprinos, tratados com uso tópico de pomada de Caesalpinia ferrea mediante análise clínica, morfométrica, histopatológica e bacteriológica do processo cicatricial até o 21 - dia de pós-operatório.

\section{MATERIAL E MÉTODO}

Quinze caprinos, adultos, machos, SRD, considerados sadios após exame clínico e mantidos em condições uniformes, foram distribuídos em três grupos para avaliação morfológica e morfométrica das feridas cutâneas nos períodos de 7, 14 e 21 dias de pós-operatório. Em cada caprino, produziram-se duas feridas cutâneas na região torácica, sendo uma em cada região lateral, divididas de acordo com o tipo de tratamento. As lesões laterais direitas do hemitórax de todos os animais formaram o grupo tratado (pomada de jucá) e as laterais esquerdas, o grupo controle (vaselina estéril).

Após a pré-medicação com sulfato de atropina e cloridrato de xilazina, na dose de $0,02 \mathrm{mg}$ $\mathrm{Kg}^{-1} \mathrm{e} 0,1 \mathrm{mg} \mathrm{Kg}^{-1}$, respectivamente, por via intravenosa, foi realizada a manipulação cirúrgica, realizou-se um bloqueio infiltrativo em " $\mathrm{L}$ " duplo, utilizando cloridrato de lidocaína sem vasoconstrictor, na dose de $7 \mathrm{mg}$ $\mathrm{Kg}^{-1}$, diluído em solução fisiológica na proporção de 1:1 (v/v). Após demarcação da área com moldes redondos (ou circulares) de papel de $4 \mathrm{~cm}$ de diâmetro (num total de $16 \mathrm{~cm}^{2}$ de área), a pele foi incidida com lâmina de bisturi e divulsionada da tela subcutânea com tesoura romba e pinça de dissecção, até a ressecção total. A hemostasia foi realizada por compressão digital e, quando necessária, pela utilização de pinças hemostáticas.

Cada falha recebeu o tratamento de acordo com a metodologia estabelecida, sendo a área cruenta totalmente preenchida com $1 \mathrm{~mL}$ de cada produto (vaselina e pomada feita com a planta). A pomada foi preparada utilizando-se o caule da Caesalpinia ferrea Mart. ex Tul. var. ferrea (jucá). A planta foi identificada e classificada no Herbário "Dárdano de Andrade Lima" da Universidade Federal Rural do Semi-Árido (UFERSA), cuja exsicata encontra-se registrada pelo número 11753.

As cascas foram colocadas para secar a temperatura ambiente por duas semanas, em seguida, levadas para estufa de secagem sob temperatura de 45 a $50^{\circ} \mathrm{C}$, por 24 horas. Posteriormente foram submetidas ao processo de moagem em moinho, sendo o pó obtido adicionado à vaselina estéril na proporção de $1: 2 \mathrm{~m} / \mathrm{m}$, sendo a pomada acondicionada em potes hermeticamente fechados e armazenados a temperatura ambiente durante todo o período experimental.

As feridas foram recobertas com compressa de gaze e atadura de crepom. Em cada animal, foi realizada diariamente a troca de curativos e aplicação dos produtos até o $21^{\circ}$ dia.

Todas as feridas foram avaliadas quanto ao aspecto clínico diariamente e nos períodos estabelecidos de pós-operatório, fotografadas, medidos os diâmetros maior e menor, empregandose paquímetro.

Na avaliação morfométrica, para a obtenção da área das feridas, utilizou-se a equação formulada por Prata et al. (1988): $A=\pi$. R. r, na qual A representa a área $\left(\mathrm{cm}^{2}\right) ; \mathrm{R}$, o raio maior e $r$, o raio menor. $O$ grau

Rev. Bras. Pl. Med., Botucatu, v.12, n.3, p.302-310, 2010. 
de contração expresso em percentual foi mensurado pela equação proposta por Ramsey et al. (1995), na qual $\mathrm{Wo}=$ área inicial da ferida e $\mathrm{Wi}=$ área da ferida no dia da biópsia:100 $\times(\mathrm{Wo}-\mathrm{Wi}) / \mathrm{Wo}=\%$ de contração.

Os resultados de área e contração das feridas foram expressos em média \pm desvio padrão, submetidos à análise de variância e ao teste de Tukey, considerando-se significativo os valores comparados ao nível de $5 \%$ de significância.

Decorridos os períodos pré-estabelecidos de 7, 14 e 21 dias de pós-operatório, foram realizadas coletas de material para avaliações histopatológica e microbiológica das feridas. As condutas cirúrgicas foram semelhantes às utilizadas no momento da produção da lesão. Retiraram-se fragmentos de 1,5 $\mathrm{cm}$ de pele através de incisão abrangendo pele íntegra e área da lesão, que foram fixados em formalina a $10 \%$ e submetidos à inclusão em parafina, para obtenção de cortes de $5 \mu \mathrm{m}$ de espessura e corados pelo método de hematoxilina-eosina (Luna, 1968).

Para avaliação bacteriológica, colheram-se amostras através de "swabs" esterilizados, na área da lesão que foram semeadas em meio líquido de BHI (Brain Heart Infusion) e meio sólido Ágar MüellerHinton e incubadas por 24 horas. Posteriormente, efetuou-se a leitura, anotando-se os aspectos de crescimento das colônias. A classificação foi realizada de acordo com as características morfológicas e morfotintoriais à técnica de Gram e observadas à microscopia de luz.

Para classificação de enterobactérias, utilizaram-se provas bioquímicas seguindo-se metodologia recomendada por Carter (1988).

\section{RESULTADO E DISCUSSÃO}

Até o 4o dia de pós-cirúrgico, o exame clínico das feridas dos animais do grupo controle apresentou hiperemia, bordos elevados e presença de exsudato de aspecto seroso e reações de desconforto, tipo dor ao toque, durante as manobras das trocas dos curativos. No mesmo período, nas feridas tratadas, observou-se discreto edema ao redor da falha cutânea, ausência de exsudato e que a pomada do jucá formou uma película rígida, espessa de coloração amarronzada, aderida a todo o leito da lesão.

Quanto à formação de crosta, observou-se que estava ausente com 24 horas, sendo que no grupo controle até o terceiro dia havia a ausência provavelmente devido ao constante trauma produzido pela aderência e retirada do curativo. Verificou-se a presença em $100 \%$ das feridas do grupo controle no 9o dia. Observou-se ainda, que esta ocupava todo o leito nos primeiros dias, com redução do tamanho a partir do $12 \circ$ dia, apresentando coloração vermelha. No grupo tratado, não foi verificada a formação da crosta devido à película que o produto formou. Resultados semelhantes foram encontrados por Monteiro (2003) e Andrade (2006), que tratando caprinos com pomadas a base de Anacardium occidentale (caju) e Jacaratia corumbensis, observaram a presença de crosta em $100 \%$ das feridas do grupo controle em torno do 9o dia e 7이a, respectivamente.

A ausência de exsudato inflamatório, edema e hiperemia comprovam que o jucá apresenta atividade antiinflamatória, bem como a película promoveu proteção física impedindo a penetração e multiplicação de microrganismo do meio externo no leito da ferida, assim como a perda de água e calor do tecido de granulação (Monteiro, 2003). Essa formação da película pode ser explicada pela riqueza de taninos (Gonzalez et al., 2004). Os taninos precipitam as proteínas dos tecidos lesados, formando um revestimento protetor que favorece a sua reparação (Jorge Neto et al., 1996), diminuindo a permeabilidade e exsudação da ferida (Brown \& Dattner, 1998; Bedi \& Shenefelt, 2002).

A vaselina e a pomada de Caesalpinia ferrea mostraram ser de fácil manuseio, porém a vaselina facilitou a aderência entre a superfície da ferida e o curativo. Tal aderência constituiu desvantagem, principalmente no grupo controle, no qual se verificou sangramento após a retirada do mesmo. Monteiro (2003) e Andrade (2006) utilizando pomada feita a partir de lanolina, também verificaram que esta provocava adesão do curativo ao leito da ferida. A aderência do curativo ao leito da ferida pode retardar o processo cicatricial por causar lesão ao epitélio durante a retirada.

Ao 7ㅇ dia de avaliação, observou-se que as medidas da ferida, nos diâmetros maior e menor, mostraram que a área encontrada apresentava médias de $12,15 \pm 1,20 \mathrm{~cm}^{2}$ e 14,08 $\pm 1,29 \mathrm{~cm}^{2}$, para os grupos controle e tratado, respectivamente. Verificouse que o percentual de contração foi muito menor no grupo tratado com média de $7,51 \%$ para este grupo e de $28,85 \%$ para o controle.

Ao 14 dia, a área de lesão, no grupo controle, teve valor médio de $3,6 \pm 0,89 \mathrm{~cm}^{2}$. No grupo do jucá, a área média foi de 9,67 $\pm 0,87 \mathrm{~cm}^{2}$. Em relação ao grau de contração, verificou-se que o controle manteve maior percentual em relação ao grupo tratado, $76,97 \%$ e $35,44 \%$, respectivamente. Esses resultados diferem daqueles encontrados por Monteiro (2003) e Andrade (2006), que tratando caprinos, encontraram percentual máximo de contração do grupo tratado maior que o do grupo controle, em torno de $80,78 \%$ e $90 \%$, respectivamente. Bem como diferem dos resultados de Estevão et al. (2007), que tratando ratos com óleo de copaíba (Copaifera langsdorffii), encontraram o percentual de contração no 14을 dia pós-cirúrgico de 95,42\% para o grupo tratado.

Rev. Bras. PI. Med., Botucatu, v.12, n.3, p.302-310, 2010. 

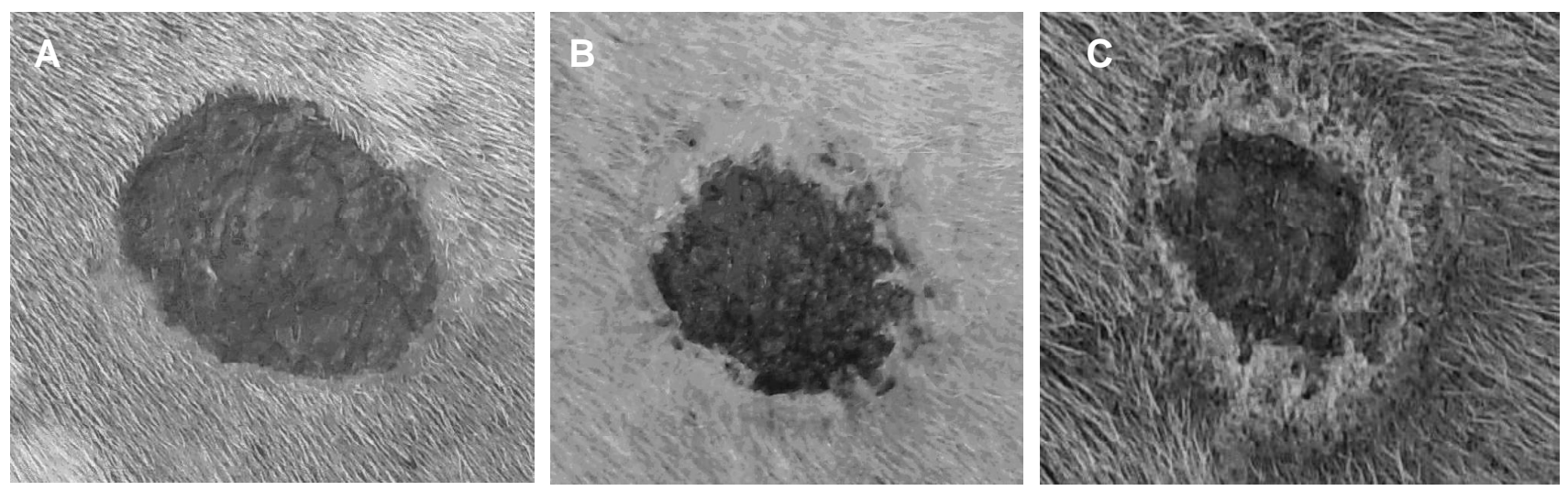

FIGURA 1. Evolução das feridas do grupo controle. A- Visualização da ferida ao 7o dia de evolução pós-cirúrgica, observando-se crosta rugosa e aderida recobrindo toda a área cruenta. B- Visualização da ferida ao 14음 dia de evolução pós-cirúrgica, observando-se crosta rugosa, tecido de granulação e tecido cicatricial recobrindo a área cruenta. C- Visualização da ferida ao 21 ㅇ dia de evolução pós-cirúrgica, observando-se crosta, tecido cicatricial e área de tracionamento da ferida.
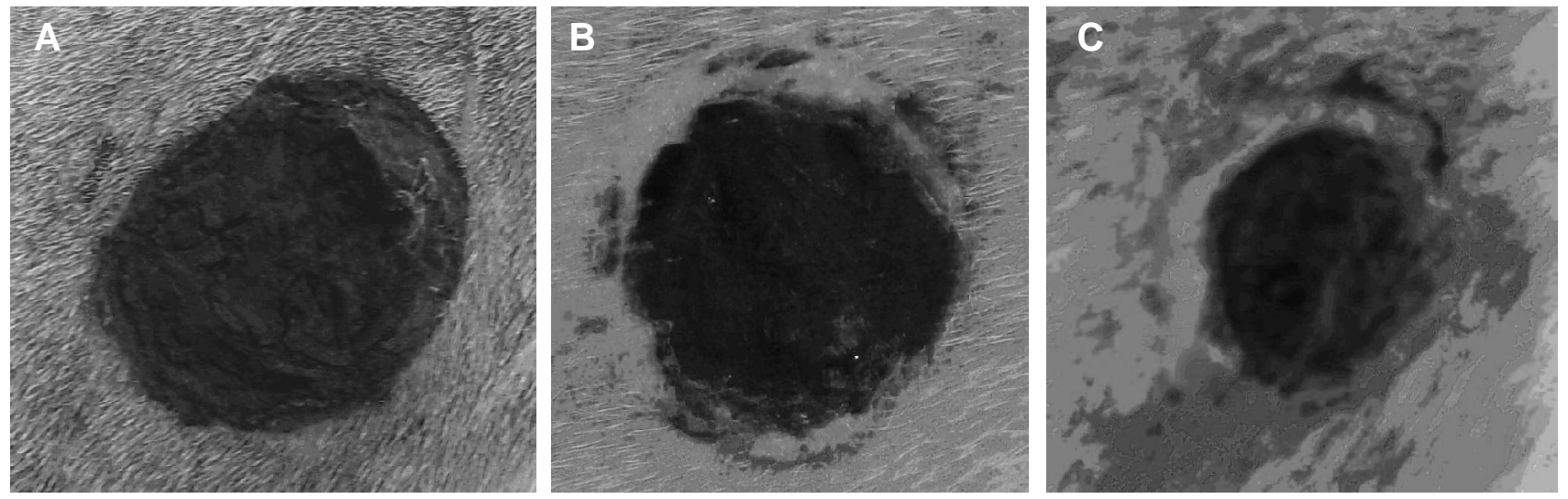

FIGURA 2. Evolução das feridas do grupo. A- Visualização da ferida ao 7o dia de evolução pós-cirúrgica, observandose. a película formada pelo jucá e crosta rugosa recobrindo toda área cruenta. B- Visualização da ferida ao 14을 dia de evolução pós-cirúrgica, observando-se a película formada pelo jucá e tecido cicatricial. C- Visualização da ferida ao 21 o dia de evolução pós-cirúrgica, observando-se ainda a presença da película e tecido cicatricial.

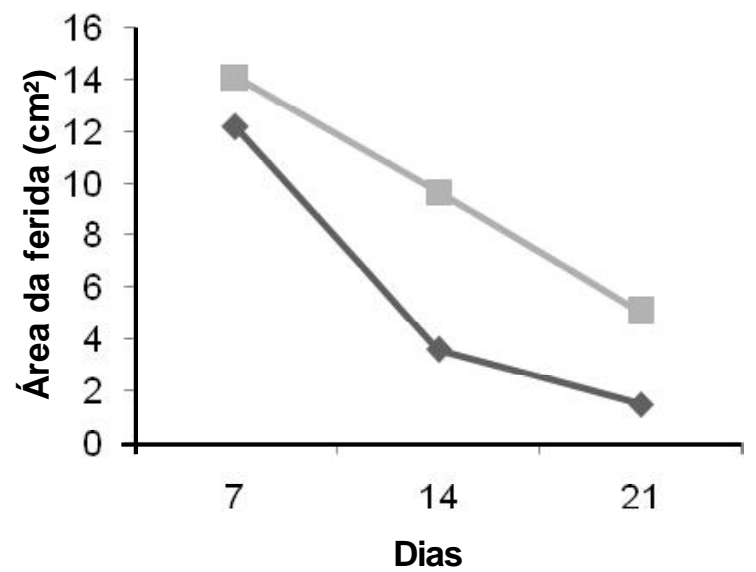

Grupo Controle

FIGURA 3. Valor médio $\left(\mathrm{cm}^{2}\right)$ da área das feridas ao 7ㅇdia $\left(T_{1}\right), 140$ dia $\left(T_{2}\right)$ e 21ㅇdia $\left(T_{3}\right)$ de evolução póscirúrgica. Letras diferentes indicam diferença significativa ao nível de $p>0,05$.

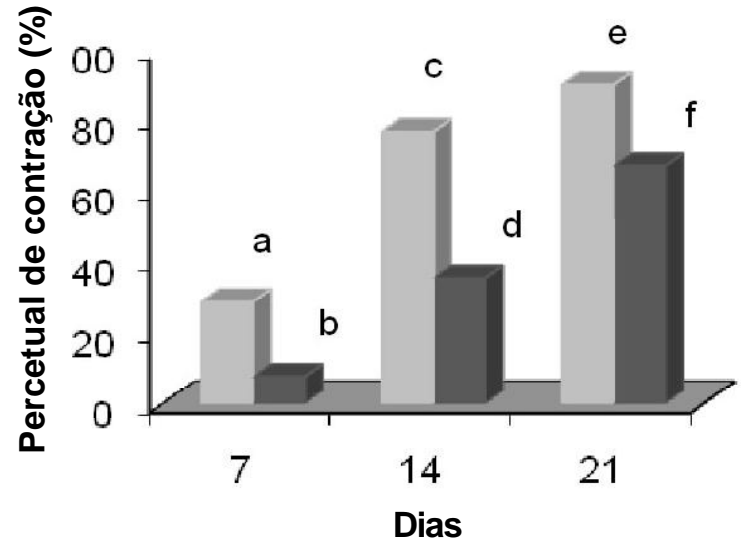

Grupo Controle Grupo Tratado

FIGURA 4. Valor médio do percentual de contração (\%) da área das feridas ao 70 dia $\left(T_{1}\right)$, 14 dia $\left(T_{2}\right)$ e 21 - dia $\left(\mathrm{T}_{3}\right)$ de evolução pós-cirúrgica. Letras diferentes indicam diferença significativa ao nível de p>0,05. 
No 21ㅇdia de experimento, observou-se que as feridas dos dois grupos ainda necessitavam de mais tempo para a resolução do processo cicatricial, porém as do grupo controle apresentavam valor médio da área em torno de 1,51 $\pm 0,24 \mathrm{~cm}^{2}$ e percentual de contração em torno de $90,25 \%$, enquanto que as feridas do grupo tratado apresentavam valores de 5,1 $\pm 1,42 \mathrm{~cm}^{2}$ e $67,17 \%$, respectivamente, para área e contração. (Figuras 3 e 4).

No sétimo dia de tratamento, a avaliação histopatológica dos fragmentos de ambos os grupos revelou a intensa presença de crostas sobre uma área de tecido de granulação intensamente infiltrado por células inflamatórias, além da formação de capilares (Figura 5). Esse processo é caracterizado como inflamação aguda, considerada reação fisiológica que indica o início do processo cicatricial (Spence \& Wong, 1997). Ocorre aumento da permeabilidade capilar e consequente migração dos polimorfonucleares para a ferida que, juntamente com o acúmulo de plasma, constituem o exsudato inflamatório (Araújo, 2001).

Avaliando-se as feridas ao 14 dia (Figuras 6 e 7), foi possível observar no grupo controle a presença de tecido de granulação fibrovascular, de focos inflamatórios, além de hiperplasia do epitélio. Já no grupo tratado, constatou-se a presença de extensas criptas epidérmicas, crosta delgada, com pouco infiltrado e tecido de granulação mais organizado quando comparado ao controle. Estes achados histológicos coincidem com os de Andrade (2006).

Ao $21^{\circ}$ dia (Figuras 8 e 9), evidenciou-se que as feridas do grupo controle apresentavam um processo de epitelização, com áreas de hiperplasia da epiderme, além de grande quantidade de vasos neoformados de pequeno e médio calibres. Pôde-se observar ainda, quantidade moderada de fibroblastos e fibras colágenas. Isso denota que, evolutivamente, essas feridas ainda necessitavam concluir o processo de epitelização. Achados semelhantes foram encontrados por Marques et al. (2004), ao tratar ovinos com óleo de girassol.

Nas feridas tratadas, foi possível constatar completo processo de reepitelização, com tecido conjuntivo apresentando grande quantidade de fibroblastos ativos, de fibras colágenas melhor organizadas e pequena quantidade de vasos sangüíneos. Segundo Mondolin \& Bevilacqua (1992) e Cândido (2001), esta fase é chamada de maturação e caracteriza-se pela deposição, agrupamento e remodelação do colágeno, bem como pela regressão endotelial.

Vale ressaltar que apesar de estatisticamente as feridas do grupo experimental apresentarem processo cicatricial inferior ao do grupo controle, evidenciado por menor grau de contração, fica claro na avaliação histopatológica que as feridas tratadas tiveram resolução da cicatrização. Isso provavelmente ocorreu devido à formação da película pela pomada do jucá, que dificultou a avaliação clínica e a mensuração dos parâmetros morfométricos, mas propiciou ambiente favorável ao processo cicatricial. Optou-se pela manutenção nas lesões, pois esta formou uma espécie de curativo natural, conferindo proteção à presença de microrganismos e miíases,
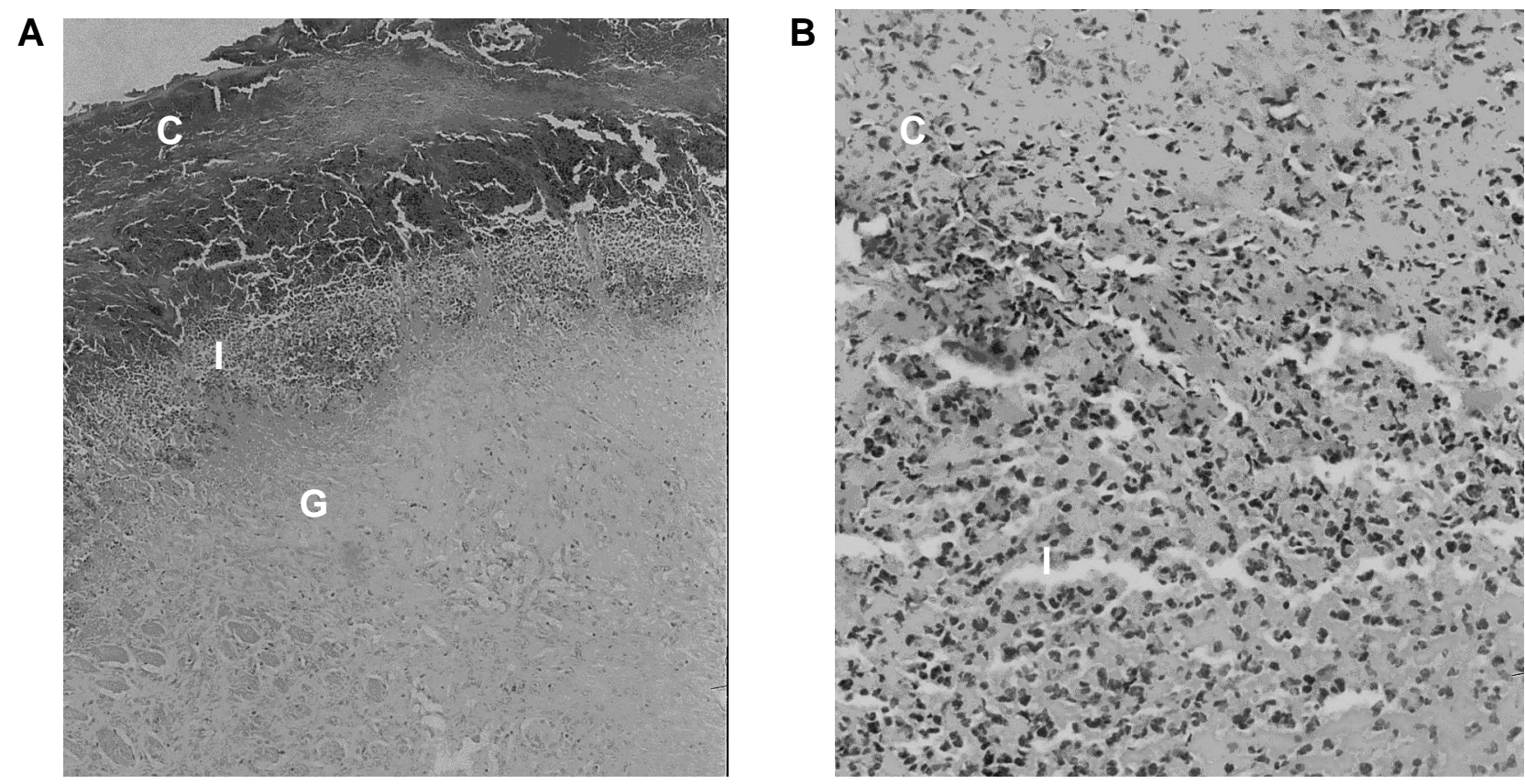

FIGURA 5. Aspecto histopatológico das feridas ao 7ㅇ dia de evolução pós-cirúrgica dos grupos controle e tratado. HE. A- aumento de 20 X; B- grupo tratado com aumento de 40 X; C, crosta; I, infiltrado inflamatório; G, tecido de granulação. 

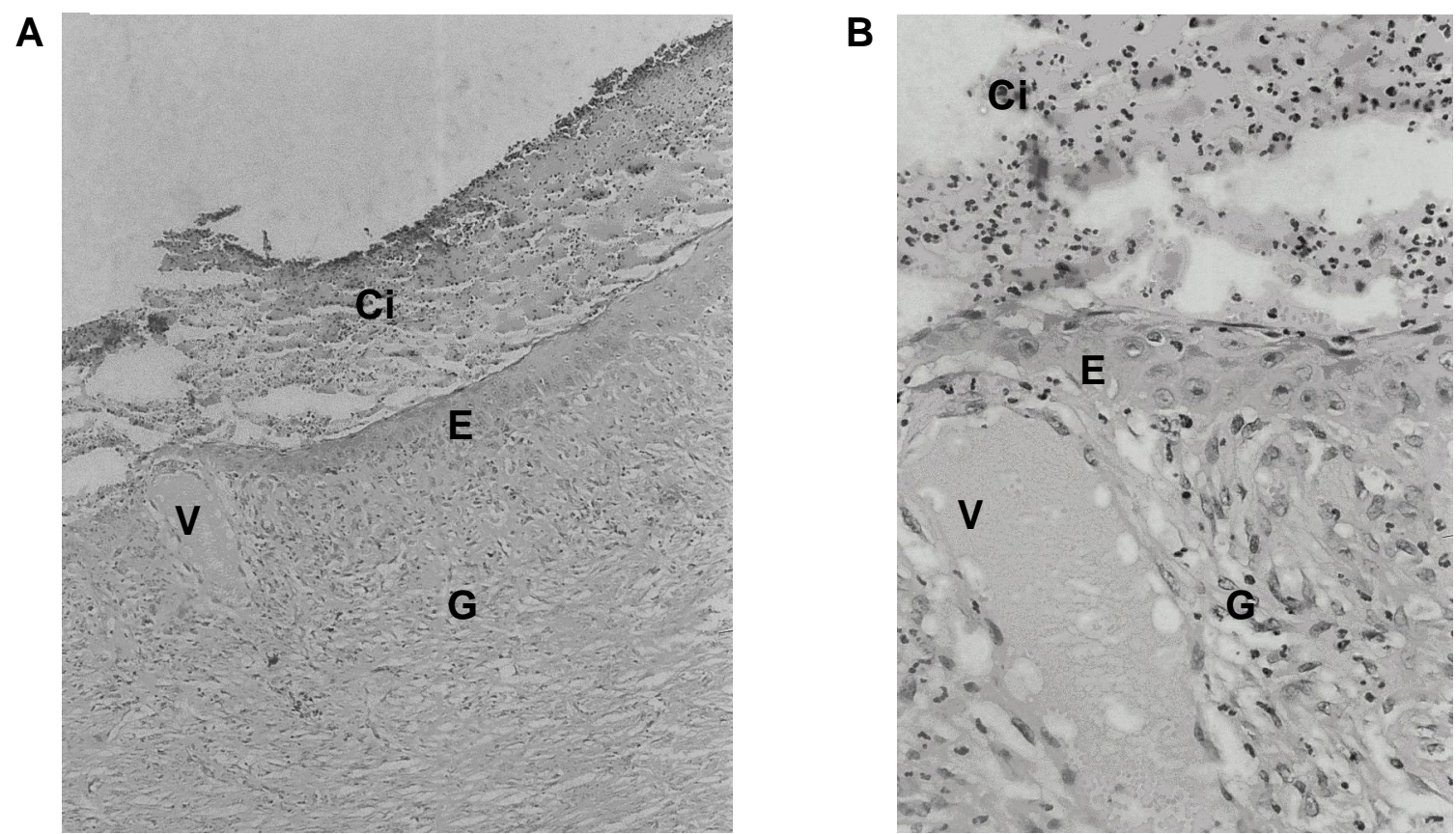

FIGURA6. Aspecto histopatológico das feridas ao 14 dia de evolução pós-cirúrgica do grupo controle. HE. A- com aumento de $10 \mathrm{X}$; B- com aumento de $40 \mathrm{X}$; Ci, crosta com infiltrado; E, Epitélio em formação; G, tecido de granulação; $\mathbf{V}$, vaso neoformado

A

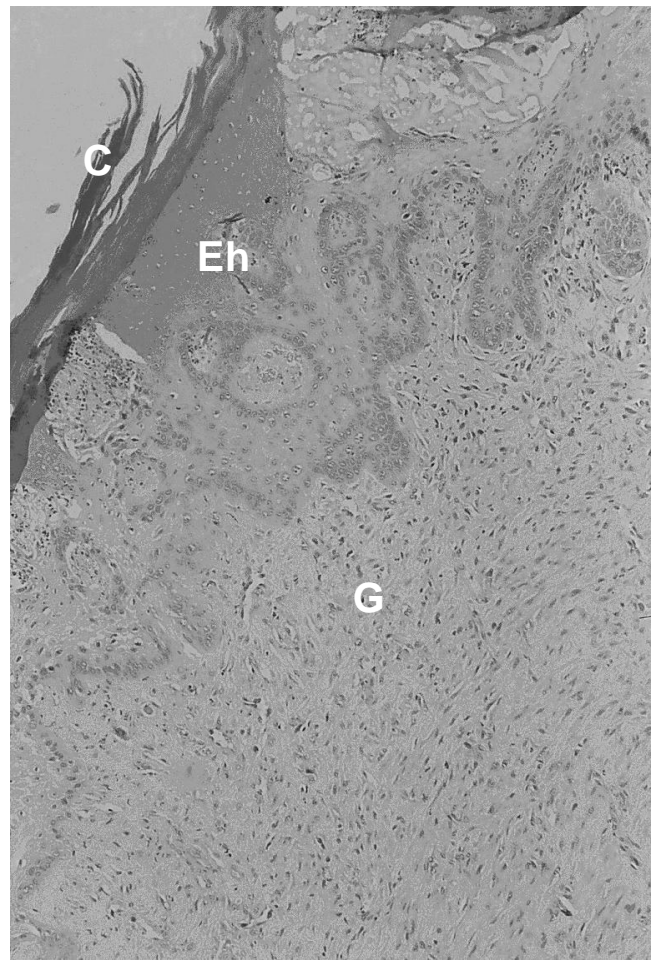

B

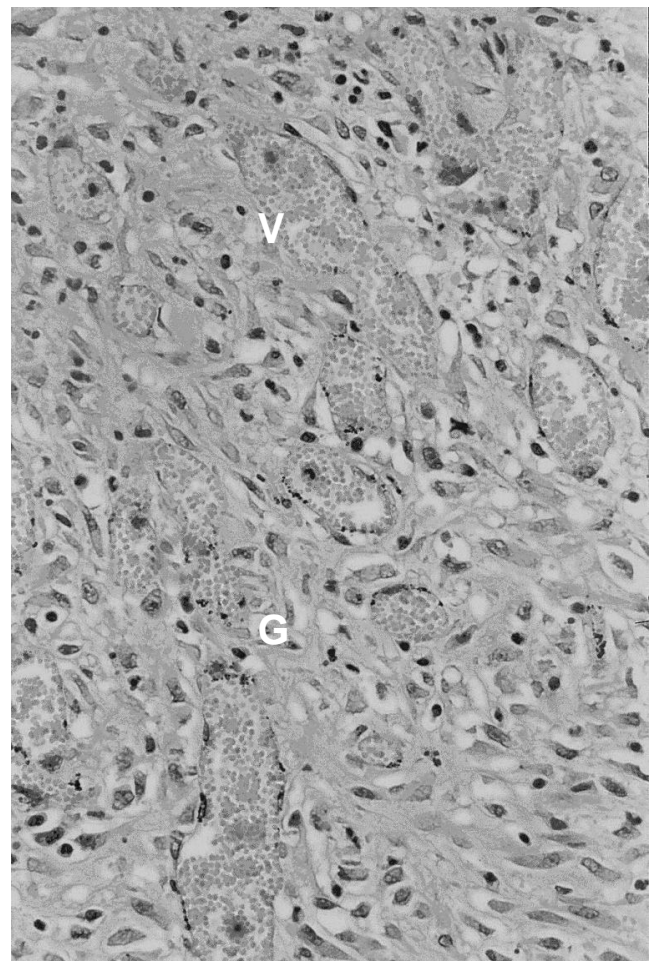

FIGURA 7. Aspecto histopatológico das feridas ao 14 dia de evolução pós-cirúrgica do grupo tratado. HE. A- com aumento de 20X; B- com aumento de 40 X; C, crosta; Eh, Epitélio hiperplásico; G, tecido de granulação; V, vaso neoformado. 


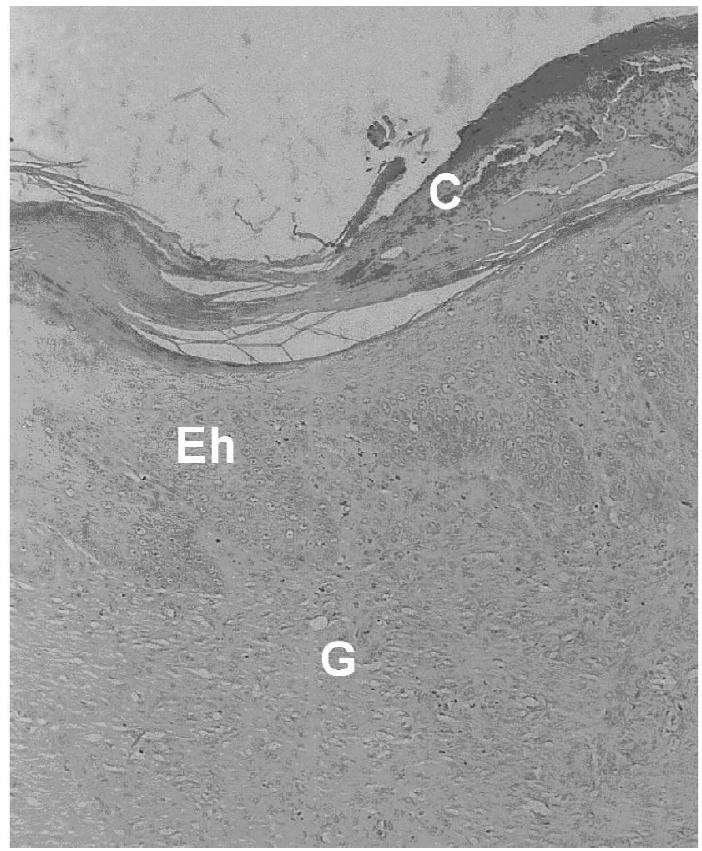

FIGURA 8. Aspecto histopatológico das feridas ao 21 dia de evolução pós-cirúrgica do grupo controle. $\mathrm{HE}$, com aumento de $10 \mathrm{X}$; C, crosta; Eh, Epitélio hiperplásico; $\mathbf{G}$, tecido de granulação.

A

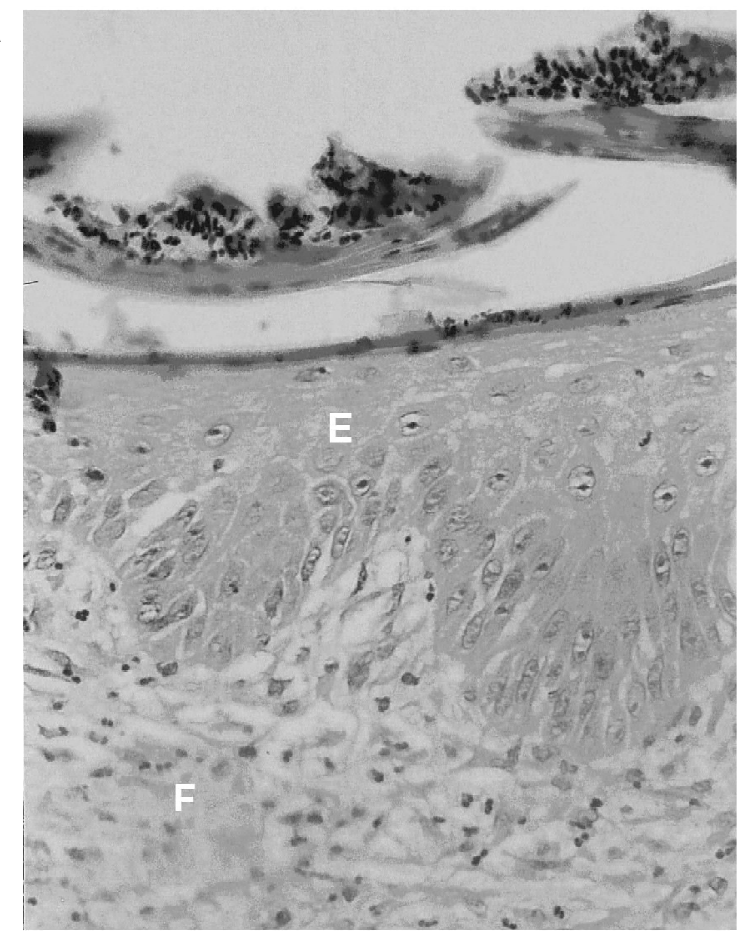

bem como barreira de proteção contra outros traumas, o que constitui vantagem, já que os caprinos são criados, na grande maioria, em regime extensivo, estando sujeitos à vegetação espinhosa da caatinga.

Nas avaliações realizadas no tempo zero, não houve crescimento microbiano nas lesões experimentais, certificando que estas foram realizadas em condições assépticas. As bactérias isoladas nos demais momentos foram agrupadas de acordo com o dia de avaliação. No 7ㅇ dia, observouse crescimento de Staphylococcus aureus, Klebisiella sp, Shigella sonnei, Escherichia coli, Salmonella sp, em ambos os grupos.

No 140 dia, observou-se crescimento de Klebisiella sp, Shigella sonnei, Escherichia coli, Salmonella sp, Proteus sp e Providence sp., em ambos os grupos. Quanto à presença de Staphylococcus aureus, esta foi encontrada apenas no grupo controle.

No 21 dia, observou-se crescimento de Klebisiella sp, Shigella sonnei, Escherichia coli, Salmonella sp, Proteus sp e Providence sp., além de Enterobacter agglomerans em ambos os grupos. Quanto à presença de Staphylococcus aureus, esta foi novamente encontrada apenas no grupo controle.

No grupo tratado, observou-se que a partir da segunda semana de tratamento já não houve crescimento da bactéria Staphylococcus aureus, - que pode indicar possível atividade antimicrobiana da Caesalpinia ferrea.

B

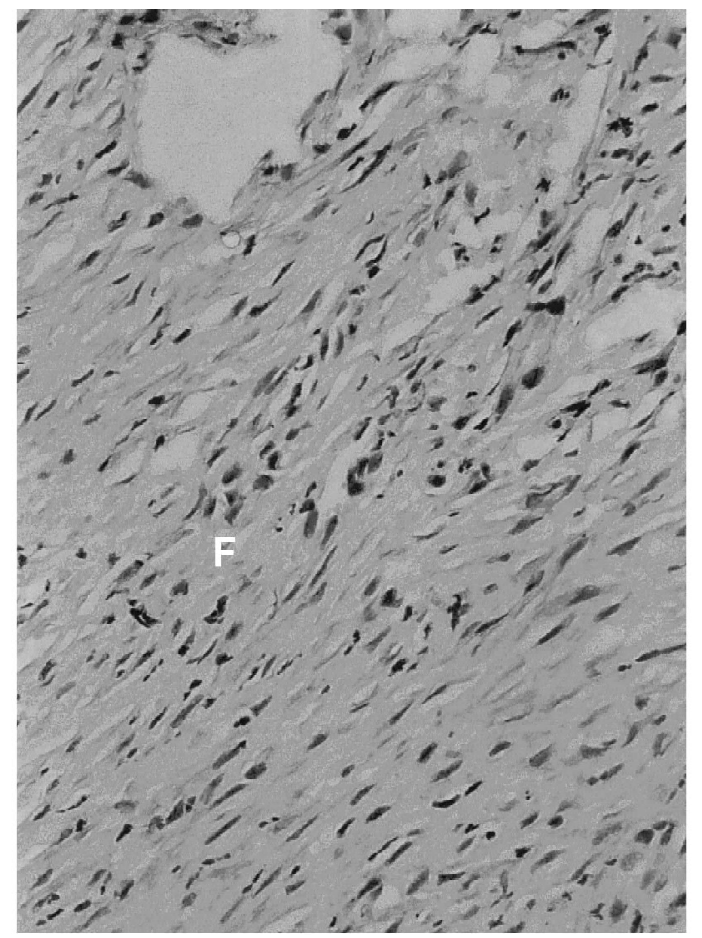

FIGURA 9. Aspecto histopatológico das feridas ao 21ㅇ dia de evolução pós-cirúrgica do grupo tratado. HE. A- aumento de 20X; B- com aumento de 40X; E, Epitélio; F, fibras colágenas. 
Pode-se presumir que não houve infecção das feridas avaliadas, já que as mesmas não apresentaram sinais sugestivos como secreção, presença de pus e de odor fétido, bem como não houve retardo no processo cicatricial.

A possível atividade antimicrobiana da Caesalpinia ferrea pode estar relacionada à presença de taninos na composição fitoquímica. Djipa et al. (2002) testaram extrato aquoso e acetônico da casca do Syzygium jambos, os quais demonstraram ter atividade antimicrobiana principalmente contra os Gram-positivos; e depois de eliminar o tanino do extrato, através de coluna de poliamida, a fração resultante foi inativa frente às bactérias testadas.

Os resultados do presente estudo permitem concluir que o uso tópico da pomada de Caesalpinia ferrea apresenta efeito significativo na cicatrização da pele de caprinos. No entanto, é importante que se amplie o estudo experimental em animais com diferentes dosagens e formulações, além do isolamento de componente (s) da planta responsável pela influência positiva no processo de reparação de tecidos.

\section{REFERÊNCIA}

ANDRADE, L.S.S. Avaliação terapêutica das pomadas do polissacarídeo do Anacardium occidentale L. e do extrato de Jacaratia corumbensis 0 . Kuntze em feridas cutâneas produzidas experimentalmente em caprinos (Capra hircus L.) Aspectos clinicos, bacteriológicos e histopatológicos. 2006. 76p. Tese (Doutorado em Ciência Veterinária) - Departamento de Medicina Veterinária, Universidade Federal de Rural de Pernambuco, Recife.

ARAÚJO, L.R.R. Estudo comparativo dos efeitos induzidos pela aplicação do laser de $\mathrm{CO} 2$ ultrapulsado e do laser de Erbium: Yttrium Aluminum Garnet, em pele de ratos. 2001. 115p. Dissertação (Mestrado em Princípios da Cirurgia) - Instituto de Pesquisas Médicas, Faculdade Evangélica do Paraná, Curitiba.

BACCHI, E.M.; SERTIE, J.A.A. Anti-ulcer action of Styrax camporum and Caesalpinia ferrea in rats. Planta Medica, v.60, p.118-20, 1994.

BACCHI, E.M. et al. Anti-ulceraction and toxicity of Styrax camporum and Caesalpinia ferrea. Planta Medica, v. 61, p.204-7, 1995.

BALBACH, A. As plantas curam. São Paulo: Três, 1972. p.302-3.

BEDI, M.K.; SHENEFELT, P.D. Herbal therapy in dermatology. Archives of Dermatology, v.138, n.2, p.23242, 2002.

BRAGANÇA, L.A.R. Plantas medicinais antidiabéticas. Niterói: EDUFF, 1996. 300p.

BRASILEIRO FILHO, G. Patologia geral. 2.ed. São Paulo: Guanabara Koogan, 1998. p.62-5.

BROWN, D.J.; DATTNER, A.M. Phytotherapeutic approaches to common dermatologic conditions. Archives of Dermatology, v.134, n.11, p.1401-4, 1998.

CÂNDIDO, L.M. Nova abordagem no tratamento de feridas. São Paulo: Senac, 2001. Disponível em: < http:// www.feridologo.com.br/acontecelivro.htm>. Acesso em: 25 jun. 2008.

CARVALHO, J.C.T. et al. Preliminary studies of analgesic and anti-inflammatory properties of Caesalpinia ferrea crude extract. Journal of Ethnopharmacology, v.53, p.175-8, 1996.

CARTER, G.R. Enterobacteriaceae. In: CARTER, G.R. Fundamentos da bacteriologia e micologia veterinária. São Paulo: Roca, 1988. cap. 17, p.145-54.

CLARK, R.A.F. Wound repair: overview and general considerations. In: CLARK, R.A.F. (Ed.). The molecular and cellular biology of wound repair. New York: Plenum Press, 1996. p.3-50.

DJIPA, C.D.; DELMÉE, M.; LECLERCQ, J.Q. Antimicrobial activity of barks extract of Syzygium jambos (L.) Alston (Myrtaceae). Journal of Ethnopharmacology, v.71, n.12, p.307-13, 2000.

ESTEVÃO, L.R.M. et al. Avaliação da contração de feridas cutâneas em ratos (Rattus norvergicus albinus) tratados com óleo de copaíba (Copaifera langsdorffii). In: JORNADA DE ENSINO, PESQUISA E EXTENSÃO. 7., 2007, Recife. Anais... Recife, 2007. Disponível em: $<$ www.adtevento.com.br/jepex/cdrom/resumos/R0751 1.pdf>. Acesso em: 25 jun. 2008.

FRASSON, A.P.Z.; BITTENCOURT, C.F.; HEINZMANN, B.M. Caracterização físico-química e biológica do caule de Caesalpinia ferrea Mart. Revista Brasileira de Farmacognosia, v.13, n.1, p.35-9, 2003.

GOMES, M. As plantas da saúde: guia de tratamentos naturais. 3.ed. São Paulo: Paulinas, 2003. 351p.

GONZALEZ, F.G.; BARROS, S.B.M.; BACCHI, E.M. Atividade Antioxidante e perfil fitoquímico de Caesalpinia ferrea MArt. In: SEMANADA FARMACÊUTICADE CIÊNCIA E TECNOLOGIA, 9., 2004, São Paulo. Anais... São Paulo: Revista Brasileira de Ciências Farmacêuticas, 2004. v.40. p.79.

HASHIMOTO, G. Illustrated encyclopedia of Brazilian medicinal plants. Kamakura: Abokk Press, 1996. p.171-7.

JORGE NETO, J. et al.Tratamento de úlcera varicosa e lesões da pele com Calendula officinalis L. e ou com Stryphnodendron barbatiman (Velloso) Martius. Revista de Ciências Farmacêuticas, v.17, p.181-6, 1996.

LIMA, E.C. et al. Atividade antifúngica de extratos obtidos de espécies de leguminoseae contra dermatófitos. Revista Brasileira de Ciências da Saúde, v.1, n.1/3, p.53-6, 1997.

LORENZI, H. Árvores brasileiras: manual de identificação e cultivo de plantas arbóreas do Brasil. Nova Odessa: Instituto Plantarum, 2002. 162p.

LUNA, L.G. Manual of histologic stanning methods of the armed forces institute of pathology. 3.ed. New York: Mc Grav Hill, 1968. 238p.

MANDELBAUM, S.H.; DI SANTIS, E.P.; MANDELBAUM, M.H.S. Cicatrização: conceitos atuais e recursos auxiliares: parte I. Anais Brasileiro de Dermatologia, v.78, n.5, p.525-42, 2003.

MARQUES, S.R. et al. The effects of topical application of sunflowr-seed oil on open wound in lambs. Acta Cirúrgica Brasileira, v.19, n.3, p.91-103, 2004.

MONDOLIN, M.; BEVILACQUA, R. Cicatrização de feridas. In: RAIA, A.; ZERBINI, E._(Eds.). Clínica Cirúrgica Alípio

Rev. Bras. PI. Med., Botucatu, v.12, n.3, p.302-310, 2010. 
Corrêa Neto. 4.ed. São Paulo: SARVIER, 1992. p.133- 8. MONTEIRO, V.L.C. Reparação tecidual de feridas cutâneas de caprinos tratadas com polissacarídeo de cajueiro Anacardium occidentale L.: estudo clinico, bacteriológico e histopatológico. 2003. 50p. Dissertação (Mestrado em Ciência Veterinária) Departamento de Medicina Veterinária, Universidade Federal de Rural de Pernambuco, Recife.

NAKAMURA, E.S. Cancer chemopreventive effects of Caesalpinia ferrea and related compounds. Cancer Letters, v.177, n.2, p.119-24, 2002.

PRATA, M.B. et al. Uso tópico do açúcar em ferida cutânea. Estudo experimental em ratos. Acta Cirúrgica Brasileira, v.3, n.2, p.43-8, 1988.
RAMSEY, D.T. et al. Effects of three occlusive dressing materials on healing of fullthickness skin wounds in dogs. American Journal of Veterinary Research, v.56, n.7, p.941-9, 1995.

SPENCE, R.J.; WONG, L. Aprimoramento da cicatrização das feridas com aloenxerto de pele humana. In: THAL, E.R. Clínica cirúrgica da América do Norte. Rio de Janeiro: Interlivros, 1997. v.3, p.727-41. XIMENES, N.C.A. Purificação e Caracterização da Lectina da Vagem da Caesalpinia ferrea (CfePL): aplicação biológica. 2004. 53p. Dissertação (Mestrado em Bioquímica - Departamento de Bioquímica) - Centro de Ciências Biológicas, Universidade Federal do Pernambuco, Recife. 